UDC 811.133.1'342.621

DOI 10.18485/primling.2015.16.2

\title{
Nataša Radusin-Bardić
}

Filozofski fakultet, Univerzitet u Novom Sadu

\section{FONETSKA VARIJACIJA U SAVREMENOM FRANCUSKOM JEZIKU: PRIMER VEZIVANJA ${ }^{1}$}

Sažetak: Vezivanje predstavlja fonetsku pojavu specifičnu za francuski jezik koja se u velikoj meri odlikuje varijacijom. Konzervativni pristup u definisanju pravila za vezivanje i nestabilnost u njihovoj primeni u svakodnevnom jeziku može se pratiti u normativnoj i deskriptivnoj literaturi od početka XX veka do danas. Ova varijacija dolazi do izražaja ne samo kod fakultativnog vezivanja, već i kod one vrste obaveznog vezivanja koja nema gramatičku i značenjsku važnost. U svakodnevnom francuskom jeziku, usled jezičke ekonomije, opšta je tendencija ka tome da se sve manje vrši vezivanje, a taj uticaj odražava se neminovno i na jezik medija o čemu javno svedoče i slušaoci francuskog nacionalnog radio servisa (Radio France).

Ključne reči: vezivanje, fonetska varijacija, francuski jezik, jezik medija

\section{Uvod}

U savremenom francuskom jeziku, među mogućim vidovima jezičkog raslojavanja, preovladava situaciono ili stilsko koje se može analizirati na svim nivoima jezičke analize. Kada je reč o analizi na fonetskom nivou, posebno se izdvaja vezivanje kao karakteristična pojava u francuskom jeziku koja je podložna varijaciji u zavisnosti od brojnih sociolingvističkih parametara. Mnoštvo jezičkih i nejezičkih faktora koji učestvuju u određivanju upotrebe vezivanja čine ovaj fenomen izuzetno složenim i otežavaju njegovo definisanje. Budući da konzervativna jezička norma teži ka tome da nametne jednoobrazni model jezičke upotrebe i da često ne odražava ukorenjene jezičke navike, kao i da, uopšteno govoreći, slabo toleriše jezičku varijaciju, prisutan je, u izvesnoj meri, raskorak između preskriptivnog i deskriptivnog aspekta vezivanja. Nastojeći da bolje shvatimo ovu jezičku pojavu, naš rad podelićemo na dva dela.

U prvom delu, definisaćemo pojam vezivanja, kako pravilnog, tako i nepravilnog, izdvojićemo njihove opšte karakteristike, a videćemo i kako je ova jezička pojava predstavljena u normativnoj i deskriptivnoj literaturi od početka XX veka do danas, sa naglaskom na fonostilistički karakter vezivanja.

U drugom delu rada, analiziraćemo upotrebu vezivanja u savremenom francu-

1 Ovaj rad je nastao u okviru projekta br. 178002 pod nazivom Jezici i kulture u vremenu i prostoru, koji finansira Ministarstvo prosvete, nauke i tehnološkog razvoja Republike Srbije. 
skom jeziku na osnovu zapažanja slušalačke publike francuskog nacionalnog radio servisa (Radio France). Naime, naš korpus činiće tekstualne poruke upućene medijatoru navedene medijske kuće poslate u periodu od 2010. do 2015. godine, a u kojima slušaoci ukazuju na brojne slučajeve u kojima je u direktnom radio programu izostavljeno očekivano vezivanje ili je ono upotrebljeno tamo gde se ne očekuje.

\subsection{Pojam vezivanja i njegove opšte karakteristike}

U savremenom francuskom jeziku, krajnji suglasnik u napisanoj reči se obično ne izgovara ukoliko ta reč stoji samostalno ili ukoliko joj sledi reč koja počinje na suglasnik ili aspirovano $\mathrm{h}$ (npr. petit $[\mathrm{p}(\mathrm{B}) \mathrm{ti}]^{2}$; un petit garçon [XptigaYsT]; un petit Hollandais [XptiClSdD]). Međutim, ukoliko se te dve reči nađu u istoj ritmičkoj grupi, te ukoliko naredna reč počinje u pisanju na samoglasnik ili nemo $h$, latentni suglasnik prethodne reči može da bude izgovoren u skladu sa određenim ortoepskim pravilima (npr. un petit ami [Xptitami], un petit hôtel [XptitotDl], [XptitCtDl]), a ta se fonetska pojava naziva "vezivanje" (fr. liaison). Ova pojava predstavlja ostatak iz starofrancuskog jezika u kome je pravopis vernije odražavao izgovor, te u kome su se krajnji suglasnici obično uvek izgovarali, nezavisno od toga da li je reč stajala samostalno ili ne, kao i nezavisno od toga koja bi eventualno bila inicijalna grafija naredne reči. U prilog ovoj tezi ide činjenica da, na primer, pridevi grand i long, prilikom vezivanja, čuvaju svoj nekadašnji izgovor koji se ogledao u staroj grafiji grant i lonc (koja je bila u upotrebi do XVI veka): un grand enfant [XgYStsfS], un long hiver [XITkivD:Y] (Grevisse, Goosse 2007: 47).

U Tabeli 1, na osnovu istraživanja Fransoa Violana (François Wioland), prikazani su najčešći suglasnici koji učestvuju u vezivanju, njihova procentualna zastupljenost u govoru i moguće grafije (Wioland 1991: 91):

\begin{tabular}{|c|c|c|c|}
\hline IZGOVOR & PROCENAT & GRAFIJA & PRIMERI \\
\hline \multirow[t]{3}{*}[\mathrm{z}]{} & \multirow[t]{3}{*}{$49,0 \%$} & $s$ & 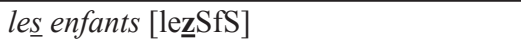 \\
\hline & & $\mathrm{x}$ & dix enfants $[$ diz $\underline{\text { SfS }}]$ \\
\hline & & $\mathrm{z}$ & chez enfants [Gez $\mathrm{SfS}]$ \\
\hline \multirow[t]{2}{*}[\mathrm{t}]{} & \multirow[t]{2}{*}{$28,2 \%$} & $t$ & un petit enfant $[\mathrm{Xptit}$ SfS] \\
\hline & & $\mathrm{d}$ & un grand enfant $[\mathrm{XgYSt} \mathrm{SfS}]$ \\
\hline [n] & $22,5 \%$ & $n$ & un enfant $[\mathrm{X} \underline{\mathbf{n} S f S}]$ \\
\hline$[\mathrm{Y}]$ & $0,25 \%$ & $\mathrm{r}$ & 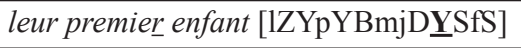 \\
\hline [p] & $0,05 \%$ & $p$ & beaucoup aimer [bokupeme] \\
\hline
\end{tabular}

Analiza Violanovog korpusa pokazuje da prilikom vezivanja najčešće dolazi do izgovora suglasnika [z] budući da je on prisutan u gotovo polovini svih zabeleženih obli-

2 U našem radu, transkripcija standardnog francuskog izgovora u Međunarodnom fonetskom pismu (Alphabet phonétique international) odgovara transkripciji datoj u elektronskom izdanju rečnika Le Petit Robert [LPR]. 
ka vezivanja. Pored suglasnika [z], u značajnoj meri zastupljeni su i suglasnici [t] i [n], dok je, između ostalog ${ }^{3}$, zanemarljiv udeo suglasnika [Y] i [p].

Jedna od osnovnih odlika vezivanja jeste ta da je ova fonetska pojava vezana za ritmičku grupu: dešava se između nenaglašenih slogova ili između nenaglašenog i naglašenog sloga u okviru ritmičke grupe, ali nikako između naglašenog i nenaglašenog sloga, odnosno na prelazu između dve ritmičke grupe (Grammont 1914: 129-130).

Pravila koja se odnose na vezivanje dele se tradicionalno na pravila koja definišu obavezno, fakultativno i zabranjeno vezivanje. Kao što im samo ime kaže, obavezno i zabranjeno vezivanje označava ono vezivanje koje, u skladu sa normativnim načelima, treba ili ne treba da se sprovodi u govoru, bez obzira na govornu situaciju. Međutim, fakultativno vezivanje direktno zavisi od situacionog raslojavanja jezika i opšteg govornog konteksta, te pruža govorniku određenu slobodu u njegovoj primeni: što je jezik negovaniji, u većoj meri je zastupljeno fakultativno vezivanje, i obrnuto, što je jezik opušteniji, fakultativno vezivanje je manje prisutno. Dok obavezno vezivanje obično podrazumeva onu vrstu vezivanja koja ima gramatičko značenje (npr. il aime [ilDm] vs. ils aiment [ilzzDm], gde se, na osnovu izgovora latentnog suglasnika [z], razlikuje indikativ glagola aimer trećeg lica jednine od trećeg lica množine), fakultativno vezivanje ima prvenstveno stilsko značenje ${ }^{4}$.

U našem radu nećemo navoditi sva pravila koja definišu obavezno, fakultativno i zabranjeno vezivanje. Zadržaćemo se samo na nekim pravilima koja su podložna varijaciji, te koja se različito tumače u normativnoj i deskriptivnoj literaturi.

\subsection{Vezivanje u normativnoj i deskriptivnoj literaturi od početka XX veka do danas}

Početkom XX veka, Moris Gramon (Maurice Grammont) je, govoreći o vezivanju, isticao da je reč o jezičkoj pojavi koja je u jeku evolucije (Grammont 1914: 130). On je govorio o tome da nove generacije generalno teže ka tome da zadrže u govoru samo onu vrstu vezivanja koja ima gramatičku funkciju, a to se posebno odnosi na razlikovanje jednine od množine (Grammont 1914: 129-130). U približno istom periodu, Anri Boš (Henri Bauche) svedoči o činjenici da se u francuskom jeziku, uopšteno govoreći, sve manje vrši vezivanje, te napominje da je ova fonetska pojava, u francuskom narodnom govoru (fr. le français populaire), izuzev u pojedinim strogo određenim slučajevima, skoro potpuno izumrla (Bauche 1920: 56).

Analizirajući pravila za vezivanje i njihovu primenu u govoru, danski romanista Kristofer Nirop (Kristoffer Nyrop) isticao je činjenicu da pravilno vezivanje podrazumeva, pre svega, dobro poznavanje pravopisnih pravila, te da stoga ne treba da nas čudi to što neuk svet često greši u govoru prilikom vezivanja (Nyrop 1902: 133), i to tako što

3 U Tabeli 1 nisu prikazani rezultati za suglasnik [k] koji, u vidu grafije $g$, izuzetno retko učestvuje u vezivanju, kao u sledećem primeru iz Marseljeze: sang impur [sSkRpy:Y]. Vezivanje uz reč long je, takođe, veoma retko, a u slučaju vezivanja, grafija $g$ u toj reči može da se izgovara kao suglasnik [k] ili [g], na primer: un long hiver [XITkivD:Y] ili [XITgivD:Y] (Léon 1972: 122).

4 Fakultativno vezivanje može da ima redundantno gramatičko značenje, kao u primeru: des femmes émancipées [defamzemSsipe]. Budući da je upotrebom neodređenog člana u množini des već jasno markiran broj, fakultativno vezivanje između imenice i prideva u množini, usled jezičke ekonomije, ne sprovodi se $u$ svakodnevnom govoru, već opstaje samo u negovanom govoru. 
umeće vezivanje tamo gde je njegova upotreba, s ortografske tačke gledišta, neopravdana, a izbegava ga tamo gde njegova upotreba nije svrsishodna, mada konzervativna jezička norma nastoji da je nametne. On je, takođe, govorio o tome da vezivanje zavisi od brojnih faktora u koje, između ostalog, spadaju sredina, društveni položaj, ritam, ton i stil, te da je, uopšteno govoreći, vezivanje odlika negovanog govora koji ima konzervativni pristup izgovoru za razliku od familijarnog govora (Nyrop 1902: 126-127).

Tendencija gubljenja vezivanja u svakodnevnom govoru, izuzev u slučajevima kada je njegovo očuvanje gramatički i semantički opravdano, nastavila se tokom čitavog XX veka, a prisutna je i danas (Peyrollaz, Bara de Tovar 1954: 173; Charliac, Motron 1998: 16; Lauret 2007 : 63). U drugoj polovini XX veka i početkom XXI veka isticao se naročito fonostilistički karakter vezivanja (Léon 1972: 133; Carton 1974: 217). Ovom tematikom posebno se bavio Pjer R. Leon (Pierre R. Léon) koji je razlikovao sledeće fonostilističke uloge vezivanja: identifikacionu i impresionističku (Léon 2001 : 151-152). Identifikaciona uloga otkriva nečiji generalno manje ili više konzervativni odnos prema izgovoru, te su, u tom smislu, starije generacije konzervativnije nego mlađe, kao što su i stanovnici ruralne sredine konzervativniji u odnosu na stanovnike urbane sredine (Léon 2001 : 156). Impresionistička uloga upućuje na svesnu upotrebu fakultativnog vezivanja u zavisnosti od toga koji se utisak u razgovoru želi postići ili koji mu se ton želi dati: formalan ili neformalan (Léon 2001 : 157). Što se više koristi fakultativno vezivanje, govor postaje sve formalniji i negovaniji, i obrnuto, što je, usled jezičke ekonomije, manje zastupljeno fakultativno vezivanje, govor postaje sve neformalniji i spontaniji (Léon, Léon 2002 : 40-41).

Kao što smo to imali prilike da vidimo, pravila za vezivanje definišu se, tradicionalno, na osnovu normativnih načela, tako što se razlikuje: obavezno, fakultativno i zabranjeno vezivanje (fr. liaison obligatoire, facultative et interdite). Međutim, krajem prošlog veka, pod uticajem varijacionističke sociolingvistike Vilijama Labova (William Labov), Pjer Ankreve (Pierre Encrevé) $)^{5}$ uvodi i deskriptivnu terminologiju prema kojoj se razlikuje: invarijabilno (kategoričko), varijabilno i eratičko vezivanje (fr. liaison invariable (catégorique), variable et erratique) (Gadet $2001: 52)$.

U nastavku našeg rada, videćemo kako se različito tretira vezivanje u zavisnosti od toga da li se posmatra sa normativne ili varijacionističke tačke gledišta. U prvom slučaju, preskriptivni pristup ogledaće se u pravilima za vezivanje koja propisuje Francuska akademija (l'Académie française), a u drugom slučaju, varijacionistički deskriptivni pristup biće utemeljen na rezultatima fonetsko-fonološke analize korpusa savremenog francuskog govornog jezika urađene u okviru međunarodnog projekta PFC (Phonologie du Français Contemporain) $)^{6}$. Korpus $P F C$, po svom obimu i značaju, spada u najveće korpuse savremenog francuskog jezika i njegovih varijeteta na frankofonom nivou (audio snimci i ortografske transkripcije) kojim su obuhvaćeni različiti registri (čitanje liste reči i kratkog teksta, poluformalni i neformalni razgovor) i približno ravnomerno zastupljeni

5 Encrevé, P. (1983). La liaison sans enchaînement. Actes de la recherche en sciences sociales 46: 39-66.

6 Rukovodioci projekta $P F C$ su: Mari-Elen Kote sa Univerziteta Laval u Kanadi (Marie-Hélène Côté, Université Laval), Žak Diran sa Univerziteta Tuluz - Žan Žores u Francuskoj (Jacques Durand, ERSS, Université de Toulouse - Jean Jaurès), Bernar Laks sa Univerziteta Zapadni Pariz-Nanter-La Defans u Francuskoj (Bernard Laks, MoDyCo, Université Paris-Ouest-Nanterre-La-Défense) i Šantal Liš sa Univerziteta u Oslu i Tromseu u Norveškoj (Chantal Lyche, Universités d'Oslo et de Tromsø). 
ispitanici oba pola, iz frankofonih urbanih i ruralnih sredina, različitih starosnih grupa (20-30 godina, 30-50 godina, 50-60 godina, 60+ godina), profesionalnih profila i nivoa obrazovanja. Projekat $P F C$ je socio-fonološkog tipa (Durand, Laks, Lyche 2002: 97-97), a u okviru njega upravo je posvećena posebna pažnja varijaciji vezivanja i nepostojanog e u savremenom francuskom jeziku. Kako bismo videli raskorak u kategorizaciji vezivanja u zavisnosti od toga da li se posmatra iz konzervativnog preskriptivnog ili iz varijacijonističkog deskriptivnog ugla gledanja, izdvojićemo samo primer vezivanja u kome je upotrebljen prezentativ: c'est + reč koja počinje na samoglasnik ili nemo h (npr. c'est un coin agréable). Prema stanovištu Francuske akademije, ova vrsta vezivanja i dalje spada u obavezno vezivanje ${ }^{7}$ dok rezultati analize korpusa projekta $P F C$ pokazuju da je pre reč o varijabilnom vezivanju, tačnije o potkategoriji one vrste varijabilnog vezivanja koje se ranije smatralo kategoričkim, tj. obaveznim, a koje se danas sprovodi u čak manje od $50 \%$ slučajeva ${ }^{8}$.

\subsection{Najčešći oblici nepravilnog vezivanja u francuskom jeziku}

U francuskom jeziku, pojam "patakes" (fr. pataquès) uopšteno označava nepravilno vezivanje između dve reči, a obično se odnosi na ono nepravilno vezivanje usled koga se čuje [z] umesto [t], npr. tu n'étais point-z-ici, kao i obrnuto, [t] umesto [z], npr. elle n'est pas-ț-ici (Mounin 2000: 251). Nepravilno vezivanje nastaje, pod uticajem analogije, kao posledica hiperkorekcije i generalizovanja vezivanja na [z] koje se često čuje

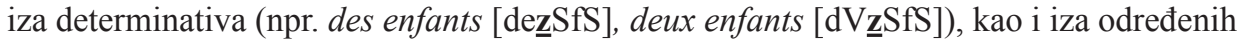
glagolskih oblika u 1. i 2. licu jednine ili 1. licu množine (npr. j'étais absent [FetDzap$\mathrm{sS}$ ], tu avais été absent [tyavDzeteapsS], nous sommes absents [nusCmzapsS]), odnosno generalizovanja vezivanja na [t] koje se često čuje posle određenih glagolskih oblika u 3. licu jednine ili množine (npr. il est arrivé [ilDtaYive], ils sont arrivés [ilsTțaYive]).

Prvi slučaj nepravilnog vezivanja, u kome se u izgovoru neopravdano umeće suglasnik [z], npr. va-ž-à lui, naziva se na francuskom velours ("velur"), a drugi, u kome se neopravdano umeće suglasnik [t], npr. il chanta-t-une chanson, naziva se na francuskom cuir (doslovno "koža"). Sinestezijski naziv "velur" motivisan je tako što se taktilni osećaj poistovećuje sa zvučnim efektom. Naime, na francuskom jeziku, velours izvorno označava materijal mek na dodir (velur, somot, kadifa, baršun), zatim sve što je meko na dodir i, najzad, ova reč postaje sinonim za utisak mekoće i blagosti, izazvan čulom ukusa, sluha i slično (LPR). Iz svega navedenog proizlazi da se nepravilno vezivanje usled koga se čuje

7 http://www.academie-francaise.fr/questions-de-langue\#46_strong-em-liaisons-em-strong $(23 / 11 / 2015)$

8 http://www.projet-pfc.net/le-francais-explique/la-liaison.html (23/11/2015).

9 Iako je poreklo pojma "patakes" nepouzdano, ono se najčešće vezuje za anegdotu ispričanu u delu Irbena Domerga (Urbain Domergue) sa početka XIX veka. Prema toj anegdoti, jedan mladić sedeo je u pozorišnoj loži između dve dame čiji su muževi bili skorojevići. Kada je na svojoj stolici pronašao lepezu, upitao ih je da li ona pripada nekoj od njih. Prva dama mu je odgovorila: Il n'est poin-z-à moi, a druga mu je odgovorila: Il n'est pa-t-à moi, na šta im je on duhovito uzvratio: Il n'est poin-z-à vous, il n'est pa-t-à vous, je ne sais patà-qu'est-ce (Domergue 1805: 465). Upotreba ovog termina zabeležena je prvi put u XVIII veku, a etimološki se sastoji od prvog dela reči: pata - nepravilnog vezivanja na [t] drugog dela negacije pas čije bi vezivanje trebalo da bude na [z] i od drugog dela reči: quès, izvedenog od pitanja: Qu'est-ce? («šta je to?», tj. «šta to znači?») (Baumgartner, Ménard 1996: 572). 
zvučni frikativ [z] akustički doživljava kao "mekše" u odnosu na nepravilno vezivanje usled koga se čuje bezvučni okluziv [t], baš kao što je i velur mekši od kože (Martinon 1913: 357). Prema pojedinim tumačenjima, navođenje "kože" u cilju označavanja nepravilnog vezivanja potiče od figurativnog izraza écorcher un mot (doslovno, "oderati reč") (TLFi), a koristi se u značenju “izobličiti, pogrešno izgovoriti neku reč", npr. il écorche tous les noms propres (u značenju: “on pogrešno izgovara sva lična imena”) (LPR). U pojedinim slučajevima, nepravilno vezivanje postaje leksikalizovano, kao što je to slučaj $\mathrm{u}$ familijarnom izrazu entre quat'z'yeux [StYBkatzjV $]^{10}$, u značenju 'u četiri oka, u poverenju, bez svedoka" (LPR, TLFi).

Spomenimo i manje poznat termin "psiloza" (fr. psilose) $)^{11}$ kojim se ponekad označava nepravilno vezivanje uz aspirovano h, npr. les-z-héros.

\section{Upotreba vezivanja u emisijama francuskog nacionalnog radio servisa (Radio France) iz perspektive slušalačke publike (2010-2015)}

U ovom delu našeg rada biće reči o tome kako slušalačka publika procenjuje upotrebu vezivanja na radio stanicama France Inter, France Info, France Bleu, France Culture, France Musique, FIP, Mouv' koje čine deo francuske nacionalne radio mreže Radio France. Naime, ova medijska kuća ima oformljen poseban sajt ${ }^{12} \mathrm{u}$ okviru koga je omogućena komunikacija između slušaoca i medijatora kome se oni obraćaju za sva pitanja, zapažanja, sugestije vezano za emitovanje sadržaja radio programa (Le médiateur : commenter, réagir, questionner). Medijator služi kao posrednik između slušalačke publike i redakcija radio stanica, a sve to u funkciji postizanja što kvalitetnijeg rada nacionalnog radio servisa koji odgovara zahtevima slušalačke publike ${ }^{13}$. Između ostalog, slušaoci komentarišu i francuski jezik koji se može čuti u radio emisijama, te su, u tom smislu, u periodu između 21. septembra 2010. godine i 3. avgusta 2015. godine uputili medijatoru 1064 poruke (filtrirane na taj način da sadrže odrednicu: langue française) ${ }^{14}$. Između ostalog, ima 59 poruka koje se odnose na vezivanje i u kojima je ukupno navedeno 86 primera nepravilnog vezivanja, a koje ćemo mi nastojati da sistematizujemo. Međutim, potrebno je, pre svega, napomenuti da ovakva vrsta podataka ne može da posluži za izvo-

10 Izgovor je dat prema rečniku LPR mada, u navedenom slučaju, dolazi do jednačenja suglasnika po zvučnosti, te bi verovatniji izgovor bio: [StYBkadzjV].

11 Termin psiloza potiče iz grčkog i označava gubitak aspiracije na početku reči (TLFi). U francuskom jeziku, o ovoj pojavi ne može se govoriti u pravom smislu te reči jer $[\mathrm{h}]$ nije fonema, niti može biti reči o aspiraciji. Razlikovanje tzv. "nemog h" ispred kog je moguća elizija i vezivanje (npr. l'homme [1Cm], les hommes [lezCm], od latinskog homo, hominis) od aspirovanog h ispred kog nije moguća elizija niti vezivanje (npr. le haricot [1BaYiko], les haricots [leaYiko], od franačkog ${ }^{\circ}$ hariôn) počiva prvenstveno na etimološkom načelu (LPR).

$12 \mathrm{http}: / /$ mediateur.radiofrance.fr (03/08/2015).

13 Funkcija medijatora ili ombudsmana u štampanim medijima javlja se prvi put 1913. godine u SAD. Ova funkcija usvojena je u Evropi tek osamdesetih godina prošlog veka, a u Francuskoj je prvi put ustanovljena 1994. godine u dnevnom listu "Le Mond" (Le Monde). Nakon toga, ova funkcija proširena je i na druge medije: na francusku nacionalnu televiziju (France Télévision) 1998. godine i na francusku nacionalnu radio mrežu (Radio France) 2002. godine. Trenutno u svetu ima stotinak medijatora, od toga petnaestak u Francuskoj. http:// mediateur.radiofrance.fr/le-mediateur-qui-quoi-comment (03/08/2015).

14 «Vos messages » (21/09/2010-03/08/2015) [filtrés par thème : langue française et par chaîne : tous] in : Le médiateur : commenter, réagir, questionner. Le médiateur. Radio France. http://mediateur.radiofrance.fr messages?page $=9 \&$ tid_1 $=156(03 / 08 / 2015)$. 
đenje naučnih rezultata jer je reč o subjektivnim slušalačkim zapažanjima koja je teško proveriti budući da nije dostupna arhiva svih zvučnih snimaka za petogodišnji period, a i često nedostaju preciznije informacije o tome o kojoj radio stanici i o kojoj radio emisiji je reč. Uprkos svojim metodološkim ograničenjima, ova vrsta podataka može svakako da ukaže na izvesne tendencije u upotrebi vezivanja u medijskom jeziku, te da podstakne opširnije fonetske analize radio programa.

\subsection{Izostavljanje obaveznog i fakultativnog vezivanja u emisijama francuskog nacionalnog radio servisa (Radio France) iz perspektive slušalačke publike (2010-2015)}

U Tabeli 2 prikazaćemo najčešće primere izostavljanja obaveznog vezivanja na koje slušaoci skreću pažnju medijatoru u svojim porukama (označeno kao "nepravilan izgovor"), te koje nije u skladu sa jezičkom normom prema tumačenju koje daje Francuska akademija:

\begin{tabular}{|c|c|c|c|c|}
\hline \multicolumn{5}{|c|}{ OSNOVNI BROJ + IMENICA (fr. adjectif numéral cardinal + substantif) } \\
\hline & PRIMER & \begin{tabular}{|c|} 
PRAVILAN \\
IZGOVOR \\
\end{tabular} & $\begin{array}{c}\text { NEPRAVILAN } \\
\text { IZGOVOR }\end{array}$ & DATUM \\
\hline 1. & un euro & {$[\mathrm{X} \underline{\mathbf{n} V Y o}]$} & [XVYo] & $10 / 10 / 2012$ \\
\hline 2. & deux euros & {$[\mathrm{dV} \underline{\mathbf{z} V Y o}]$} & [dVVYo] & $28 / 05 / 2014$ \\
\hline 3. & trois euros & [tYwazVYo] & [tYwaVYo] & $10 / 10 / 2012$ \\
\hline 4. & dix euros & [dizVYo] & [diVYo] & $28 / 05 / 2014$ \\
\hline 5. & vingt euros & [vRtivYo] & [vRVYo] & $22 / 10 / 2015$ \\
\hline 6. & quatre-vingts euros & [katYBvRzVYo] & [kat(YB)vRVYo] & $10 / 10 / 2012$ \\
\hline 7. & cent euros & [sStVYo] & [sSVYo] & $10 / 10 / 2012$ \\
\hline 8. & deux cents euros & [dVsSzVYo] & [dVsSVYo] & $17 / 05 / 2014$ \\
\hline 9. & trois cents euros & [tYwasSzzVYo] & [tYwasSVYo] & $10 / 07 / 2013$ \\
\hline 10. & cinq cents euros & [sRsSz $\underline{\mathrm{z} Y \mathrm{Y}}]$ & [sRsSVYo] & $20 / 07 / 2012$ \\
\hline 11. & $\begin{array}{l}\text { deux mille six cents } \\
\text { hôtels }\end{array}$ & 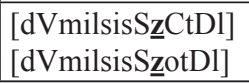 & $\begin{array}{l}\text { [dVmilsisSCtDl] } \\
{[\mathrm{dVmilsisSotDl}]}\end{array}$ & $14 / 07 / 2013$ \\
\hline \multicolumn{5}{|c|}{ PREZENTATIV C'EST $+\ldots\left(\right.$ fr. présentatif $\left.« c^{\prime} e s t »+\ldots\right)$} \\
\hline & PRIMER & $\begin{array}{c}\text { PRAVILAN } \\
\text { IZGOVOR }\end{array}$ & $\begin{array}{l}\text { NEPRAVILAN } \\
\text { IZGOVOR }\end{array}$ & DATUM \\
\hline 1. & c'est elle & {$[\mathrm{sD} \underline{\underline{t} D l}]$} & [sDDl] & $17 / 05 / 2014$ \\
\hline 2. & c'est un film & [sDtXfilm] & [sDXfilm] & $06 / 05 / 2014$ \\
\hline 3. & c'est un scandale & [sDtXskSdal] & [sDXskSdal] & $29 / 10 / 2014$ \\
\hline
\end{tabular}

U gore datu tabelu nisu uneti oni primeri izostavljenog obaveznog vezivanja koji se samo jednom javljaju u porukama upućenim medijatoru, te koji se mogu smatrati lapsusom u direktnom radio programu (npr. un homme izgovoreno [XCm] umesto [Xㅡㅡㄹ (10/07/2013), ils ont été izgovoreno [ilT(t)ete] umesto [ilzT(t)ete] (22/10/2015), c'est 
très utile izgovoreno [sDtYDytil] umesto [sDtYDżtil] (06/05/2014), d'autres amis izgovoreno [dotYami] umesto [dotYBżami] (06/05/2014)).

Na osnovu primera datih u Tabeli 2 možemo zaključiti da najčešće dolazi do izostavljanja obaveznog vezivanja kada se brojevi nađu u determinantskoj upotrebi ispred imenica koje počinju na samoglasnik ili na nemo h, a to naročito dolazi do izražaja kada se iza broja nalazi imenica koja se često koristi u govoru, kao što je to slučaj sa monetom Evropske unije: evrom (fr. euro). Osim toga, primetno je i izostavljanje obaveznog vezivanja iza prezentativa c'est kome sledi reč koja počinje na samoglasnik ili nemo h, a na ovu pojavu, kao što smo to imali prilike ranije da vidimo, ukazuju i rezultati analize korpusa $P F C$.

U Tabeli 3 prikazaćemo najčešće primere izostavljanja fakultativnog vezivanja na koje slušaoci skreću pažnju medijatoru u svojim porukama (označeno kao "nevezivanje") smatrajući ga neprimerenim. Primeri sa fakultativnim vezivanjem navedeni su u skladu sa pravilima datim u normativnoj gramatici Le bon usage (Grevisse, Goosse 2007: 4849), kao i prema tumačenju koje daje P. R. Leon (Léon 1972: 131-132):

\begin{tabular}{|c|c|c|c|c|}
\hline \multicolumn{5}{|c|}{ IMENICA + PRIDEV U MNOŽINI (fr. substantif + adjectif au pluriel) } \\
\hline & PRIMER & VEZIVANJE & NEVEZIVANJE & DATUM \\
\hline 1. & des êtres humains & [dezDtYBzzymR] & [dezDtYymR] & $11 / 04 / 2012$ \\
\hline 2. & les lettres étrangères & [lelDtYBzetYSFD:Y] & [lelDtYetYSFD:Y] & $02 / 05 / 2014$ \\
\hline 3. & les affaires étrangères & [lezafDYzetYSFD:Y] & [lezafDYetYSFD:Y] & $18 / 05 / 2011$ \\
\hline 4. & les relations humaines & [leYBlasjTzymDn] & [leYBlasjTymDn] & $18 / 05 / 2011$ \\
\hline 5. & les portes ouvertes & [lepCYtBzuvDYt] & [lepCYtuvDYt] & $07 / 04 / 2012$ \\
\hline \multicolumn{5}{|c|}{ IZJAVNA REČENICA: $Q U A N D+\ldots$ (fr. phrase déclarative $:$ «uand» $+\ldots)$} \\
\hline & PRIMER & VEZIVANJE & NEVEZIVANJE & DATUM \\
\hline 1. & quand il est venu & {$[\mathrm{kS} \underline{\operatorname{til}} \mathrm{Dv}(\mathrm{B}) \mathrm{ny}]$} & {$[\mathrm{kSilDv}(\mathrm{B}) \mathrm{ny}]$} & $10 / 07 / 2013$ \\
\hline 2. & quand ily a & [kStilja] & [kS(i l)ja] & $05 / 12 / 2014$ \\
\hline 3. & quand on & {$[\mathrm{kSt} T]$} & {$[\mathrm{kST}]$} & $17 / 12 / 2012$ \\
\hline
\end{tabular}

U gore datu tabelu nisu uneti oni primeri izostavljenog fakultativnog vezivanja koji se retko javljaju u porukama upućenim medijatoru, te za koje bi se moglo reći da su manje stilski markirani (npr. ils sont intéressants izgovoreno [ilsTRteYesS], a ne [ilsTtRteYesS] (06/05/2014), je voudrais avoir izgovoreno [FBvudYDavwa:Y], a ne [FBvudYDzavwa:Y] (06/05/2014)).

Kada je reč o primerima fakultativnog vezivanja koji se navode u Tabeli 3, zanimljivo je videti kako ih tumače različiti autori. S jedne strane, P. R. Leon naziva obaveznim ono vezivanje $u$ kome je, u izjavnoj rečenici, upotrebljen prilog quand ispred reči koja počinje na samoglasnik ili nemo h (Léon 1972: 131), a sa druge strane, u 14. izdanju gramatike Le bon usage, ova vrsta vezivanja nije podvedena pod obavezno vezivanje već se samo kaže da je reč o vezivanju koje se generalno preporučuje (Grevisse, Goosse 2007: 49). Na osnovu rezultata korpusa $P F C$, ova vrsta vezivanja podvodi se pod varijabilno vezivanje. Povodom fakultativnog vezivanja u kome su upotrebljeni imenica i pridev u 
množini, P. R. Leon kaže da je u pitanju «neprirodan tip vezivanja» u govornom jeziku (fr. liaison anormales dans le style parlé), ali da ga je moguće čuti u negovanom jeziku (Léon 1972: 131). Rezultati korpusa PFC takođe pokazuju da je ova vrsta vezivanja prilično retka u govoru.

\subsection{Patakes u emisijama francuskog nacionalnog radio servisa (Radio France) iz perspektive slušalačke publike (2010-2015)}

U Tabeli 4 prikazaćemo najčešće primere patakesa na koje slušaoci skreću pažnju medijatoru u svojim porukama (označeno kao «nepravilan izgovor»). U pitanju je vezivanje koje nije u skladu sa jezičkom normom prema tumačenju koje daje Francuska akademija, a u okviru koga se razlikuje nepravilno vezivanje na [z] (fr. velours), nepravilno vezivanje na [t] (fr. cuir) i nepravilno vezivanje uz aspirovano h (fr. psilose):

\begin{tabular}{|c|c|c|c|c|}
\hline \multicolumn{5}{|c|}{$\begin{array}{l}\text { Tabela 4: Nepravilno vezivanje (fr. pataquès) u u emisijama francuskog nacionalnog radio servi- } \\
\text { sa (Radio France) iz perspektive slušalačke publike (2010-2015) }\end{array}$} \\
\hline \multicolumn{5}{|c|}{ NEPRAVILNO VEZIVANJE NA [z] (fr. velours) } \\
\hline & PRIMER & $\begin{array}{l}\text { PRAVILAN } \\
\text { IZGOVOR }\end{array}$ & $\begin{array}{l}\text { NEPRAVILAN } \\
\text { IZGOVOR }\end{array}$ & DATUM \\
\hline 1. & quatre hommes & {$[\mathrm{katYCm}]$} & {$[\mathrm{kat}(\mathrm{YB}) \underline{\mathbf{z} C m}]$} & $27 / 04 / 2011$ \\
\hline 2. & huit éducateurs & [PitedykatZ:Y] & [Pi(t) $\underline{\text { zedykatZ:Y] }}$ & $10 / 12 / 2010$ \\
\hline 3. & neuf étrangers & [nZfetYSFe] & {$[\text { nZf } \underline{z} \text { etYSFe }]^{15}$} & $21 / 01 / 2013$ \\
\hline 4. & vingt euros & [vRtVYo] & {$[\mathrm{vR}(\mathrm{t}) \underline{\mathrm{z} V Y o}]$} & $02 / 02 / 2011$ \\
\hline 5. & vingt huit états & [vRtPiteta] & 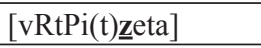 & $09 / 09 / 2014$ \\
\hline 6. & trente auteurs & [tYStotZ:Y] & [tYStzotZ:Y] & $03 / 04 / 2014$ \\
\hline 7. & cent euros & {$[\mathrm{sStVYo}]$} & [sSzVYo] & $23 / 11 / 2011$ \\
\hline 8. & cent histoires & [sStistwa:Y] & [sSzistwa:Y] & $15 / 05 / 2013$ \\
\hline 9. & cent oliviers & [sStClivje] & [sSzClivje] & $19 / 01 / 2012$ \\
\hline 10. & $\begin{array}{l}\text { cent cinquante oeu- } \\
\text { vres }\end{array}$ & [sSsRkS.tZ:vY] & [sSsRkS.tzzZ:vY] & $08 / 10 / 2013$ \\
\hline 11. & trois mille amis & [tYwamilami] & [tYwamilzami] & $23 / 06 / 2015$ \\
\hline 12. & dix mille indiens & [dimilRdjR] & [dimilzRdjR] & $22 / 04 / 2014$ \\
\hline 13. & $\begin{array}{l}\text { vingt-deux mille } \\
\text { abonnés }\end{array}$ & [vRtdVmilabCne] & [vRtdVmilzabCne] & $01 / 02 / 2014$ \\
\hline 14. & $\begin{array}{l}\text { quelques jours plus } \\
\text { tard à peine }\end{array}$ & [kDlkBFu.Y plytaYapDn] & $\begin{array}{l}\text { [kDlkBFu.Y } \\
\text { plytaYzapDn] }\end{array}$ & $10 / 12 / 2010$ \\
\hline \multicolumn{5}{|c|}{ NEPRAVILNO VEZIVANJE NA [t] (fr. cuir) } \\
\hline & PRIMER & $\begin{array}{l}\text { PRAVILAN } \\
\text { IZGOVOR }\end{array}$ & $\begin{array}{l}\text { NEPRAVILAN } \\
\text { IZGOVOR }\end{array}$ & DATUM \\
\hline 1. & il va être & [ilvaDtY] & [ilvatDtY] & $10 / 12 / 2010$ \\
\hline \multicolumn{5}{|c|}{ NEPRAVILNO VEZIVANJE UZ ASPIROVANO H (fr. psilose) } \\
\hline
\end{tabular}

15 U Tabeli 4, u okviru nepravilnog vezivanja na [z], u primerima 3, 6 i 10 označenim kao "nepravilan izgovor", doći će do jednačenja do zvučnosti: [nZvzetYSFe], [tYSdzotZ:Y], [sSsRkS.dzZ:vY]. 


\begin{tabular}{|c|c|c|c|c|}
\hline & PRIMER & $\begin{array}{l}\text { PRAVILAN } \\
\text { IZGOVOR }\end{array}$ & $\begin{array}{l}\text { NEPRAVILAN } \\
\text { IZGOVOR }\end{array}$ & DATUM \\
\hline 1. & un handicap & [XSdikap] & [XńnSdikap] & $16 / 11 / 2014$ \\
\hline 2. & des handicapés & [deSdikape] & [dezSdikape] & $16 / 11 / 2014$ \\
\hline 3. & à tout hasard & [atuaza:Y] & [atutaza:Y] & $12 / 11 / 2014$ \\
\hline 4. & $\begin{array}{l}\text { une personne était } \\
\text { harcelée }\end{array}$ & [ynpDYsCn etDaYsBle] & $\begin{array}{l}\text { [ynpDYsCn } \\
\text { etDtaYsBle] }\end{array}$ & $13 / 12 / 2011$ \\
\hline 5. & un drapeau était hissé & [XdYapo etDise] & [XdYapo etDtise] & $13 / 12 / 2011$ \\
\hline
\end{tabular}

U gore datu tabelu nije posebno unet primer nepravilnog vezivanja imenice i prideva u jednini koji se javlja samo u jednom slučaju: le président américain izgovoreno [1BpYezidStameYikR] umesto [1BpYezidSameYikR] (10/01/2014).

Kao što se to vidi u Tabeli 4, među primerima patakesa, češće je nepravilno vezivanje na [z], nego na [t]. Nepravilno vezivanje na [z] posebno se često javlja kada se brojevi nađu u determinantskoj upotrebi ispred imenica koje počinju na samoglasnik ili na nemo h. Kada se ovim primerima doda izostavljeno obavezno vezivanje $u$ istom položaju (videti Tabelu 2), onda možemo zaključiti da je, u savremenom francuskom jeziku, generalno nestabilna upotreba vezivanja uz brojeve. Naime, od ukupno 86 primera nepravilnog vezivanja na koje slušaoci francuskog nacionalnog radio servisa (Radio France) ukazuju medijatoru, čak 53 primera odnose se upravo na greške u vezivanju u slučaju determinantske upotrebe brojeva ispred imenica (31 primer izostavljanja obaveznog vezivanja i 22 primera patakesa).

U Tabeli 4, posebno je izdvojena kategorija nepravilnog vezivanja koja se često javlja u govoru, a odnosi se na vezivanje uz reči koje počinju na aspirovano h. Budući da jedino poznavanje etimologije omogućava razlikovanje nemog h (poreklom iz latinskog jezika) uz koje je obavezno vezivanje od aspirovanog h (poreklom iz germanskih jezika) uz koje je zabranjeno vezivanje, u govoru često dolazi do generalizacije njihove upotrebe, odnosno do izjednačavanja svakog $\mathrm{h}$ sa nemim $\mathrm{h}$, pa samim tim i do nepravilnog vezivanja.

\subsection{Opšta zapažanja slušalačke publike francuskog nacionalnog radio servisa (Radio France) o upotrebi vezivanja u radio programu (2010-2015)}

Na kraju drugog dela našeg rada, izdvojićemo nekoliko upečatljivih primera komentara koje slušaoci francuskog nacionalnog radio servisa (Radio France) upućuju medijatoru. Među njima, brojni komentari svedoče o činjenici da je generalno sve manje zastupljeno vezivanje u radio programu na francuskom jeziku:

(1) Depuis plusieurs années la majorité des présentateurs et parfois quelques chroniqueurs à France Inter (que j'écoute) ne font plus ou presque les liaisons en parlant. $(05 / 03 / 2015)$

ili da vezivanje nije u skladu sa jezičkom normom:

(2) Combien à longueur de journée se prennent la langue dans les dents du fond 
et nous massacrent allègrement nos belles liaisons françaises. Ä̈e nos pauvres oreilles! (14/02/2012)

Komentarišući vezivanje, slušaoci se pozivaju i na činjenicu da familijarni jezički registar koji se koristi u radio programu nije primeren nacionalnom radio servisu:

(3) Le Français parlé par nombre de journalistes n'est pas celui que l'on pourrait attendre d'une chaîne nationale. (14/02/2012)

Slušaoci podsećaju medijatora i na ulogu koju nacionalni medijski servis ima $u$ očuvanju francuskog jezika i u pružanju modela izražavanja:

(4) [...] Et pourtant, sans doute votre boulangère, comme ma crémière, ne fontelles pas de liaison. A qui la faute? Ma réponse est : d'abord à ceux qui parlent en public - donc entre autres, aux journalistes de presse parlée. Bien sûr, les journalistes sont des personnes comme tout le monde, mais ne croyezvous pas que le fait qu'ils sont entendus par des millions de gens leur donne une responsabilité particulière? (16/07/2013)

Povodom brojnih poruka slušaoca koje svedoče o nepravilnoj upotrebi vezivanja $\mathrm{u}$ radio programu (naročito kada je reč o upotrebi brojeva ispred imenica), medijator zaključuje da je, uprkos čestim intervencijama i obraćanju redakcijama, teško ispraviti ukorenjene navike u govoru:

(5) Vous avez raison. Force est de constater que nos appels répétés (et ceux des responsables des rédactions) à respecter les liaisons ne portent pas pleinement leurs fruits! La tendance est si lourde dans l'ensemble des usages quotidiens de notre société qu'elle devient bien difficile à endiguer. (19/01/2012)

\section{Zaključak}

U savremenom francuskom jeziku, iako vezivanje predstavlja jedan od najizraženijih oblika fonetske varijacije, ova pojava nije skorijeg datuma. U našem radu, nakon što smo objasnili poreklo vezivanja, videli smo da se nestabilnost u primeni normativnih pravila za obavezno, zabranjeno i fakultativno vezivanje beleži u literaturi koja se bavi fonetikom francuskog jezika od početka XX veka do danas. Međutim, važno je napomenuti da nisu sva pravila za vezivanje podložna varijaciji. Naime, s jedne strane, stabilna su ona pravila za vezivanje koja imaju funkcionalnu, tj. gramatičku i značenjsku vrednost, a sa druge strane, nestabilna su ona pravila (naročito za fakultativno vezivanje) koja imaju, pre svega, fonostilistički karakter. Iz svega navedenog proizlazi da, u svakodnevnom govoru, usled jezičke ekonomije, postoji opšta tendencija ka tome da se gubi ona vrsta vezivanja koja nije nužna za pravilno prenošenje poruke.

Preduslov za pravilno vezivanje, pored poznavanje opštih pravila, podrazumeva 
i dobro poznavanje francuskog pravopisa. Kao što smo ranije imali prilike to da vidimo, usled nepoznavanja pravopisa, ali i paradigmatske generalizacije i hiperkorekcije, često dolazi do patakesa, tj. do nepravilnog vezivanja. Ova pojava često se vezuje za narodni govor, ali sreće se i u raznim drugim jezičkim registrima, naročito kada postoji izvesna neujednačenost u pravopisnim pravilima, kao što je to, na primer, slučaj sa brojevima gde postoje izuzeci od opšteg pravila za tvorbu množine (npr. deux cents euros, ali deux mille euros, itd.).

Varijacija u vezivanju je, pod uticajem sve većeg prodora govornog jezika u medije, prisutna, između ostalog, i u emisijama francuskog nacionalnog radio servisa (Radio France). Zahvaljujući zvaničnom sajtu ove medijske kuće, koji je oformljen u svrhu uspostavljanja komunikacije sa slušaocima i dobijanja povratnih informacija vezano, između ostalog, i za kvalitet francuskog jezika koji se emituje na radio talasima, saznajemo kako slušaoci procenjuju upotrebu vezivanja u radio programu. Njihova zapažanja, koja bi svakako bilo potrebno proveriti i potkrepiti opširnijim fonetsko-fonološkim analizama radio programa, govore o izvesnim tendencijama u vezivanju koje se, u značajnoj meri, podudaraju sa fonetsko-fonološkim analizama savremenog francuskog govornog jezika, među kojima i sa analizom korpusa $P F C$.

\section{Literatura}

Bauche, H. (1920). Le langage populaire. Paris : Payot.

Carton, F. (1974). Introduction à la phonétique du français. Paris, Bruxelles, Montréal : Bordas, Collection „Études“.

Charliac, L. \& A.-C. Motron (1998). Phonétique progressive du français avec 600 exercices. Paris : CLE International.

Domergue, U. (1805). Manuel des étrangers amateurs de la langue françoise, ouvrage utile aux François eux-mêmes. Paris : Guilleminet.

Durand, J., Bernard Laks \& Chantal Lyche (2002). La Phonologie du français contemporain (PFC) : usages, variétés et structure. In: C. Pusch \& W. Raible (eds.) Romanistische Korpuslinguistik - Korpora und gesprochene Sprache / Romance Corpus Linguistics - Corpora and Spoken Language. Tübingen : Gunter Narr Verlag, 93-106.

Gadet, F. (2001). Le français ordinaire. Paris : Armand Colin, Collection U, Série Linguistique, № 375 .

Grammont, M. (1914). Traité pratique de prononciation française. Paris : Librairie Delagrave.

Grevisse, M. \& A. Goosse (2007). Le bon usage. Grammaire française. Bruxelles : Éditions De Boeck, J. Duculot (14édition).

Lauret, B. (2007). Enseigner la prononciation du français : questions et outils. Paris : Hachette FLE.

Léon, P.-R. (1972). Prononciation du français standard. Aide-mémoire d'orthoépie à l'usage des étudiants étrangers. Paris : Didier.

Léon, P.-R. (2001). Phonétisme et prononciations du français. Paris : Nathan Université, Collection Fac, Linguistique.

Léon, M. \& P. Léon (2002). La prononciation du français. Paris : Nathan Université, Collection linguistique 128, № 143.

Nyrop, K. (1902). Manuel phonétique du français parlé. Copenhague : Det Nordiske Forlag, Ernst Bojesen ; Leipzig : Otto Harrassowits ; Paris : Alphonse Picard \& Fils. 
Peyrollaz, M. \& M.-L. Bara de Tovar (1954). Manuel de phonétique et de diction françaises. Paris : Librairie Larousse.

Wioland, F. (1991). Prononcer les mots du français. Des sons et des rythmes. Paris : Hachette, F.L.E., Collection Autoformation.

\section{Rečnici}

Baumgartner, E. \& P. Ménard (1996). Dictionnaire étymologique et histoire de la langue française. Paris : Le Livre de Poche, Librairie Générale Française.

LPR - Le Petit Robert. Version électronique du Nouveau Petit Robert, dictionnaire alphabétique et analogique de la langue française. Version 2.1 (2001). [CD-ROM]. Paris : Dictionnaires Le Robert / VUEF.

Mounin, G. (dir.) (2000). Dictionnaire de la linguistique. Paris : Quadrige, PUF (3e édition).

TLFi - Le Trésor de la langue française informatisé (2012). Nancy : CNRTL (Centre National de Ressources Textuelles et Lexicales), ATILF (Analyse et traitement informatique de la langue française). http://www.cnrtl.fr/definition/ (03/02/2016).

\section{Elektronski izvori}

Coquillon A. «La liaison » in : PFC Enseignement. Le français expliqué. Projet Phonologie du Français Contemporain - Enseignement du Français (2004-2016). Nanterre : MoDyCo UMR 7114 CNRS Université Paris X Nanterre. http://www.projet-pfc.net/le-francais-explique/la-liaison. html (23/11/2015).

Le médiateur : commenter, réagir, questionner. Le médiateur. Radio France. http:// mediateur.radiofrance.fr $(03 / 08 / 2015)$.

«Le médiateur: Qui? Quoi? Comment?» in:Lemédiateur : commenter, réagir, questionner. Le médiateur. La médiation. Radio France. http://mediateur.radiofrance.fr/le-mediateur-qui-quoicomment (03/08/2015).

"Liaisons » in : La langue française. Questions de langue. Académie française. http:// www.academie-francaise.fr/questions-de-langue\#46_strong-em-liaisons-em-strong (23/11/2015).

« Vos messages » (21/09/2010-03/08/2015) [filtrés par thème : langue française et par chaîne : tous] in : Le médiateur : commenter, réagir, questionner. Le médiateur. Radio France. $\mathrm{http}: / /$ mediateur.radiofrance.fr/messages?page=9\&tid_1=156 (03/08/2015). 


\section{Nataša Radusin-Bardić}

\section{LA VARIATION PHONÉTIQUE EN FRANÇAIS CONTEMPORAIN : L'EXEMPLE DE LA LIAISON}

Résumé: En français contemporain, la liaison représente un phénomène de variation par excellence. Traditionnellement, les règles régissant la liaison définissent les cas où son emploi est obligatoire, interdit ou facultatif et c'est justement ce dernier qui varie considérablement en fonction du niveau de langue : plus la situation de communication devient formelle, plus la liaison facultative devient marquée, et inversement. Hormis ce champ de variation toléré par la norme langagière, il y a aussi des cas où la liaison continue à être traditionnellement considérée comme obligatoire par la norme conservatrice, mais qui devient en réalité de plus en plus rare dans la langue courante. Dans ce sens-là, en remplaçant des termes prescriptifs (la liaison obligatoire, interdite et facultative) par des termes descriptifs inspirés par la linguistique variationniste de William Labov (la liaison invariable/catégorique, erratique et variable), on parle des cas de liaison catégorique devenue variable (par exemple, le présentatif «c'est» devant un mot commençant par une voyelle ou par un h muet). La fluctuation des règles de liaison en français contemporain n'échappe pas non plus à la langue des médias dont témoignent des auditeurs de Radio France dans leurs commentaires adressés au médiateur et disponibles sur le site Internet de ce service public national.

Mots clés: liaison, variation phonétique, français, langue des médias 